\title{
Scintigraphic Evaluation of Endocarditis
}

\author{
Wilhelm P. Mistiaen ${ }^{1,2, *}$ \\ ${ }^{1}$ Dept of Health and Social Care Artesis-Plantijn University College Antwerp, Belgium \\ ${ }^{2}$ Faculty of Medicine and Health Sciences, University of Antwerp, Belgium
}

\begin{abstract}
Introduction: Infective endocarditis (IE) is a very heterogeneous condition for several reasons. The diagnosis can be notoriously difficult. A delay in diagnosis can have severe consequences. Even proper application of the Duke criteria cannot solve all cases. For this reason, positron emission tomography / computer tomography (PET/CT) with 18F-fluorodesoxyglucose (18FDG) has been proposed in the 2015 guidelines of the European Society of Cardiology. What has been the effect of these guidelines thus far?

Methods: A probe of the literature has been performed in PubMed, from 2016 on using the search terms "endocarditis AND PET"

Results: One hundred items were identified, of which 41 documents could be retained. However, only 16 were original series, mostly with low numbers. The other manuscripts were editorials, comments, reviews and "image vignettes". $\mathrm{PET} / \mathrm{CT}$ increased the sensitivity of the Duke criteria in cases of prosthetic valve endocarditis (PVE), but in a much lesser degree in native valve endocarditis (NVE). Patient preparation should be standardized in order to reduce the uptake of 18FDG by the myocardium. This includes low carbohydrate - high fat diet, fasting and unfractionated heparin administration. Furthermore, image acquisition and processing (quantification, correction for attenuation, taking into account implanted metallic materials) should also be standardized. Effects of antibiotics (negative imaging results before cure) and inflammation (especially healing after operation and use of biological glue materials) should be taken into account. Radiolabeled white blood cell scintigraphy could be a valuable adjunct in these cases. The detection of extracardiac foci (especially tumors which can serve as port of entry and septic emboli) is an additional advantage.

Conclusion: PET/CT seems a valuable tool to increase the accuracy in diagnosing IE, especially PVE. Early postoperative cases must be interpreted with caution. To confirm the value of PET/CT, the major centers should standardize their method. This allows comparison of results of larger patient groups, which could be collected in the International Collaboration of Endocarditis - Prospective Cohort Study. Nuclear cardiologists should also be included in "endocarditis teams.
\end{abstract}

Keywords: Infective endocarditis, Positron emission tomography, Native valve, Valve prosthesis, Duke criteria.

\section{INTRODUCTION}

Infective endocarditis (IE) is a very heterogeneous condition. Well-known variables are the causative agents, the site and severity of the infection. The latter includes presence or absence of paravalvular involvement, abscesses, fistulae, chordal rupture, valve perforation and heart block as sign of intra-cardiac destruction. This can lead to congestive heart failure, which is one of the strongest predictors of poor outcome [1]. Other variables are the effect on other organs through septic emboli. This can lead to devastating complications such as stroke but can also remain silent. Last but not least, IE can occur as native valve endocarditis (NVE) or after the implantation of prosthetic valves, prosthetic valve endocarditis (PVE) or electronic cardiac devices cardiac device related IE (CDRIE). The outcome of IE depends highly on timely and adequate intervention and can be influenced by other factors such as referral and treatment bias [1].

"Address correspondence to this author at the Division of Physiotherapy, Faculty of Medicine and Health Sciences, University of Antwerp, Campus Drie, Eiken, Universiteitsplein 1, 2610 Antwerp, Belgium;

Tel: 32326527 82; Fax: 32326551 20;

E-mail: wilhelm.mistiaen@ap.be; wilhelm.mistiaen@uantwerpen.be
The diagnosis of IE can be notoriously difficult. The ESC added in their guidelines the need for an "endocarditis team" and suggested also the use of nuclear imaging [2]. Positron emission tomography (PET) with 18-fluoro-desoxyglucose (18-FDG) as marker for increased metabolism can serve such as in inflammation, infection and malignancies [3]. Another method is labeling of white blood cells (WBC)] with a radionuclide tracer which is considered as more specific for infection [4]. The question to answered is in how far these guidelines had already an effect on management of IE.

\section{METHODS}

A small screening probe through PubMED from 2016 to 2018 was performed using the search terms "endocarditis AND PET". Case studies, congenital heart defects and no free access manuscripts were excluded. Included were all papers (original articles, reviews, meta-analyses, editorials, technical comments) dealing with native IE (NVE), prosthetic valve IE (PVE) and cardiac electronic device related IE (CDRIE). 


\section{RESULTS}

With these search terms, one hundred items were found. Forty-one documents could be retained. Of these, only 16 were original articles. There were 9 reviews, 7 editorials, two meta-analyses and 7 manuscripts of another type. The original articles are listed in Table 1. Most of them are smaller series: eleven articles have less than 100 patients, five of them are larger. Most of them are retrospective and observational and are aimed to assess the added value of PET/CT scan. One paper does not focus on IE but on the uptake pattern after valve replacement [5]. Nevertheless, this paper has been included because this offers valuable information about interpreting

Table 1: The Original Series

\begin{tabular}{|c|c|c|c|c|}
\hline Author & $\mathbf{n}$ & Type & Aim & Conclusion \\
\hline Amrawi 2016 [35] & 35 & CDRIE & Search for septic embolism & $\begin{array}{c}\text { emboli in } 10 / 35 \text { (sometimes clinically silent } \\
\text { or not visible on CT) }\end{array}$ \\
\hline Fagman 2016 [19] & 27 & $\begin{array}{l}8 \text { PVE } 19 \text { controls } \\
\text { retr. cc. }\end{array}$ & $\begin{array}{l}\text { comparison with non-infected } \\
\text { valve prostheses }\end{array}$ & $A \cup C=0.90$ \\
\hline Granados 2016 [9] & $\begin{array}{l}21 \\
29 \\
30\end{array}$ & $\begin{array}{c}\text { NVE } \\
\text { PVE } \\
\text { CDIE } \\
\text { prosp. }\end{array}$ & $\begin{array}{l}\text { evaluate diagnostic accuracy } \\
\text { of PET/CT in suspected IE }\end{array}$ & $\begin{array}{c}\text { limited value in NE PET-CT is a valuable } \\
\text { adjunct for doubtful cases other foci and } \\
\text { neoplasms }\end{array}$ \\
\hline $\begin{array}{c}\text { Jimenez-Ballvé } 2016 \\
\text { [18] }\end{array}$ & 41 & PVE/ CDRIE & $\begin{array}{l}\text { usefulness of } \mathrm{PET} / \mathrm{CT} \\
\text { interpretation criteria }\end{array}$ & $\begin{array}{c}\mathrm{AUC}=0.71 \text { importance of patient } \\
\text { preparation }\end{array}$ \\
\hline Salomaki 2016 [7] & 23 & PVE 16 NVE 7 & search for paravalv. infection & $\begin{array}{l}\text { PET/CT sensitive in PVE but limited value in } \\
\text { NVE }\end{array}$ \\
\hline Kokalova 2017 [36] & 13 & PVE & evaluation of PET & $\begin{array}{c}\text { high spec, sens. and PPV low NPV; reveals } \\
\text { extra cardiac foci }\end{array}$ \\
\hline Kouijzer 2017 [38] & 273 & Q-fever & diagnostic value of PET/CT & $\begin{array}{l}\mathrm{PET} / \mathrm{CT} \text { provides important diagnostic and } \\
\text { prognostic information in } \mathrm{Q} \text { fever }\end{array}$ \\
\hline Machelart 2017 [31] & 10 & Bentall graft infection & use of PET/CT during follow-up & $\begin{array}{l}\text { impact of PET on clinical management is } \\
\text { unclear }\end{array}$ \\
\hline Mathieu 2017 [5] & 51 & $\begin{array}{l}\text { non-infected } \\
\text { prosthetic heart } \\
\text { valves* }\end{array}$ & $\begin{array}{c}\text { features of PET/CT uptake } \\
\text { pattern }\end{array}$ & $\begin{array}{l}\text { often homogenous } \\
\text { mild-to-moderate tracer accumulation }\end{array}$ \\
\hline Pizzi 2017 [39] & 25 & $\begin{array}{l}\text { cong. HD with } \\
\text { prosthesis } \\
\text { prospective }\end{array}$ & $\begin{array}{l}\text { value } \mathrm{PET} / \mathrm{CTA} \text { in complex } \\
\text { anatomy }\end{array}$ & $\begin{array}{l}\text { Duke criteria are low sens. and NPV; } \\
\text { PET/CTA improves these with accuracy }\end{array}$ \\
\hline Scholtens 2017 [27] & 13 & PVE & $\begin{array}{c}60 \text { ' v. } 150 \text { ' imaging improves } \\
\text { accuracy? }\end{array}$ & late imaging is prone to false + : caution! \\
\hline Ariaans 2018 [37] & $\begin{array}{l}234 \\
379\end{array}$ & $\begin{array}{l}\text { before SBC } \\
\text { after SBC }\end{array}$ & $\begin{array}{l}\text { effect of SBC for S. aureus } \\
\text { bacteremia }\end{array}$ & PET and TEE have added value \\
\hline Diemberger 2018 [6] & 105 & CDRIE, prosp. obs. & $\begin{array}{l}\text { evaluate extended CDIE by } \\
\text { PET/CT on survival }\end{array}$ & $\begin{array}{c}\text { survival improves by correct identification } \\
\text { CDRIE by PET/CT }\end{array}$ \\
\hline Gomes 2018 [40] & 176 & $\begin{array}{l}\text { obs. NVE, PVE \& } \\
\text { CDRIE }\end{array}$ & $\begin{array}{c}\text { comparing echo, CTA \& } \\
\text { PET/CT }\end{array}$ & $\begin{array}{l}\text { modalities are complementary for these } \\
\text { conditions }\end{array}$ \\
\hline kouijzer 2018 [14] & 88 & NVE retrosp. & value of $\mathrm{PET} / \mathrm{CT}$ & $\begin{array}{c}\text { negative PET/CT does not exclude NVE } \\
\text { useful for extra-cardiac }\end{array}$ \\
\hline Swart 2018 [21] & $\begin{array}{c}160 \\
77\end{array}$ & $\begin{array}{l}\text { PVE suspected } \\
\text { controls* blinded }\end{array}$ & $\begin{array}{l}\text { improving accuracy \& } \\
\text { performance; excluding conf. }\end{array}$ & $\begin{array}{c}\text { low inflammatory activity (prolonged } \\
\text { antibiotic) is a confounder }\end{array}$ \\
\hline
\end{tabular}

Abbreviations: cc. case control; CDRIE: cardiac device related infective endocarditis; conf.: confounders; cong. HD: congenital heart disease; echo: echocardiography NVE: native valve endocarditis; NPV: negative predictive value; obs.: observational; paravalv.: paravalvular; PET/CT: positron emission tomography / computer tomography; PPV: positive predictive value; prosp.: prospective; PVE: prosthetic valve endocarditis; retr.: retrospective; SBC: structured bedside consultation; sens.: sensitivity; spec.: specificity; SUV: standard uptake value; TBR: target-tobackground-ratio; TEE: transesophageal echocardiography.

* indication for PET/CT: oncologic, suspected but at hindsight excluded PVE, vasculitis.

NOTE: TBR = SUV max valve / SUV mean blood pool. 
postoperative PET/CT images. Several issues are addressed for this interesting imaging modality.

\section{Increase in Accuracy by PET/CT}

Most important is the added value of PET/CT in different types of IE (NVE, PVE and CDRIE). The reason is the numbers of false positive and false negatives of the Duke criteria for IE. Late recognition of this condition can lead to increased mortality. Correct identification improves survival in patients with electronic cardiac implants and IE [6]. PET/CT leads to an increased sensitivity, especially in patients with PVE [7-13]. Adding PET/CT could increase the sensitivity of the modified Duke criteria to about $90 \%$. A negative PET/CT does not exclude the presence of NVE [14] because its sensitivity is low [4]. The reason could be the low number of inflammatory cells in vegetation in NVE [4]. PVE is associated with perivalvular involvement and tissue destruction and clearly has an added value for pseudo-aneurysms and abscesses [11]. With PET/CT, up to $90 \%$ of the undecided cases of PVE could be reclassified [15] and misdiagnosis can be reduced [16]. These methods should not replace the more classic imaging techniques but should be integrated into decision algorithms $[15,17]$. Using PET/CT could increase the area under the curve in the receiver-operator-curve analysis to 0.71 [18] and even $0.90[19,20]$ in PVE. Prolonged antibiotic treatment in patients with PVE, however, leads to lowered inflammatory activity, which could serve as a confounder [21]. In cases of doubt, PET/CT could be complemented with WBC scintigraphy [4]. It is also important to keep in mind that echocardiography or cardiac CT is needed to document vegetation in PVE $[2,11]$.

\section{Patient Preparation}

The use of 18-FDG is based on metabolic trapping of this radiolabeled agent since it cannot be further processed. This is more outspoken in metabolic active tissues. In physiologic conditions, this is for example the myocardium. For this reason, patient preparation is needed. This includes a low carbohydrate - high fat diet, and administration of unfractionated heparin, to suppress the myocardial $18-F D G$ uptake $[16,18,22$, 23]. The image processing should make use of the maximum standard uptake value (SUV-max) and of target to background ratio (TBR), taking into account both parameters show a great variability of overlap between patients with and without PVE. Cut-off values at 4.4 [24] or lower [21] have been proposed. Correction of attenuation [25] should be performed and the proximity of metallic prosthetic material, if present, should be taken into account. The timing of imagingtaking is considered as useful $[2,26,27]$, but not by all [24].

\section{Inflammation V. Infection}

Infection and inflammation of other causes such as postoperative healing and foreign body reaction should be discerned because of their different management and outcome. Scintigraphic techniques, based on radiolabeled WBC can serve as complement for distinction between sterile inflammation and infection $[4,15,25,28]$. Although PET/CT has the advantage of detecting cells with high metabolic activity and has a short acquisition time, the technique does not distinguish inflammation from infection. IE is more probable in presence of an intense and focal perivalvular uptake of 18-FDG but biological surgical glues and suture material $[25,29]$ can also produce this effect. Sterile postoperative inflammation at the border between the host tissue and prosthetic material can exists for some months in an animal model [26], and sometimes even for years on PET/CT imaging [25]. Moreover, without proper preparation, the adjacent myocardium also shows a high uptake [4]. Nevertheless, PET/CT allows a reclassification of possible IE into definitive IE or rejection of the diagnosis [4]. Radiolabeled WBC accumulate in areas of bacterial infection such as IE and shows high sensitivity (up to $90 \%$ ) and a $100 \%$ specificity. These inflammatory cells are absent in vegetation, which are usually small [4]. WBC scintigraphy has the disadvantage of handling blood products in-vitro and a longer preparation time. As for PET/CT, WBC scintigraphy can also detect metastatic infections due to septic emboli [28]. This is important in postoperative situations where early PVE is suspected. One series studied non-infected prosthetic valves [5] thereby providing useful imaging data: inflammation as part of a healing process often shows a homogenous, mild-tomoderate and steady accumulation of the tracer [29]. This can be important in situations with suspected early PVE in the first weeks after valve replacement. Waiting to perform PET/CT does not solve the problem of false positive imaging, hence there is no reason to wait according to some authors [26], but not to others [29]. However, on the one hand, one should be aware for suture material [29], and surgical adhesive material $[2,13,25,29]$, which show more intense accumulation. 
On the other hand, the level of inflammation in true IE can be lowered by prolonged use of antibiotics [21, 30], which can result in false negative results on PET/CT. Moreover, it is not clear if PET/CT can be used to assess the effect of antibiotics [15]. Especially in early postoperative PVE, foreign body reaction and a low degree of inflammation due to antibiotic treatment are not always easy to distinguish [4, 24]. In certain conditions, such as infection of a Bentall graft, the added value of PET/CT is unclear [31]. Remission of "hot spots" does not equal cure of IE [2]. Some other sources might cause false interpretation. One of the more known anomalies is lipomatous interatrial hypertrophy [2, 24, 32]. Correlation of these metabolic data with anatomical findings in CT such as abscesses, fistulae, pseudo-aneurysms and thickening of leaflets, and vegetation is invaluable in the distinction of IE [29].

\section{Extra-Cardiac Foci}

One of the extra bonuses of PET/CT are the extracardiac foci. These included the possible mechanisms of development of IE. Malignancies, especially those of the digestive tract could serve as port of entry for bacteria $[33,34]$ such as streptococcus gallolyticus and enterococci. The included original series $[9,14,35,36]$ also mention the detection of extra-cardiac manifestations of the disease. Even in patients without clinical suspicion, up to $65 \%$ of the cases show such possible emboli [37]. In a meta-analysis, this has been $17 \%$ [12]. The use of PET/CT is especially useful for those patients in whom an MRI is not possible because of a previously implanted cardiac electronic device $[15,30]$.

\section{CONCLUSIONS}

$\mathrm{PET} / \mathrm{CT}$ is a useful imaging method for inflammatory cardiovascular conditions and it complements more conventional imaging methods [11]. PET/CT shows the combined metabolic and anatomical data. Still, in the last years only a few large series of over 100 patients have been published; most series are small, observational and retrospective and therefore prone to bias (3). Randomized controlled trials are difficult to design for ethical reasons. Larger multicenter based series over some expanded time are needed, in order to collect enough data. A standardized method for patient preparation, imaging acquisition and processing is needed. This can best be undertaken through the International Collaboration on Endocarditis - Prospective Control Study ICE-PCS. Pitfalls such as inflammatory repair in the early postoperative period and low inflammation - without cure - after prolonged antibiotic treatment can lead to misinterpretations. Moreover, the method is useful in patients with PVE, but much less with NVE.

It was also remarkable to see more reviews, editorials and comments of several types compared to original series between 2016 and 2018. This stresses even more the need for prospective multicenter collection of data over an extended period. Only two larger series could be identified. One series showed the value of the structured bedside consult in cases of bacteremia with $S$. aureus [37] and also showed the value of $P E T / C T$, even in patients with suspected PVE in the early postoperative course. Standardization of every step in the PET/CT protocol is mandatory. The method can be incorporated in decision algorithms for NVE and PVE separately $[15,17]$, by specially assigned "endocarditis teams" [4].

\section{REFERENCES}

[1] Mistiaen W. What are the main predictors of in-hospital mortality in patients with infective endocarditis: a review, Scandinavian Cardiovascular Journal. https://doi.org/10.1080/14017431.2018.1433318

[2] Scholtens AM, Swart LE, Verberne HJ, Tanis W, Lam MGEH, Budde RJP. Confounders in FDG-PET/CT Imaging of Suspected Prosthetic Valve Endocarditis. JACC Cardiovasc Imaging 2016; 9: 1462-1465.

https://doi.org/10.1016/j.jcmg.2016.01.024

[3] Lawal I, Sathekge M. F-18 FDG PET/CT imaging of cardiac and vascular inflammation and infection. British Medical Bulletin 2016; 120: 55-74. https://doi.org/10.1093/bmb/ldw035

[4] Hyafil F, Rouzet F, Le Guludec D. Nuclear imaging for patients with a suspicion of infective endocarditis: Be part of the team! J Nucl Cardiol 2017; 24: 207-211. https://doi.org/10.1007/s12350-015-0369-z

[5] Mathieu C, Mikaïl N, Benali K, lung B, Duval X, Nataf P et al. Characterization of $18 \mathrm{~F}-F$ luorodeoxyglucose Uptake Pattern in Noninfected Prosthetic Heart Valves. Circ Cardiovasc Imaging 2017; 10: e005585 https://doi.org/10.1161/CIRCIMAGING.116.005585

[6] Diemberger I, Bonfiglioli R, Martignani C, Graziosi M, Biffi M, Lorenzetti $\mathrm{S}$, et al. Contribution of PET imaging to mortality risk stratification in candidates to lead extraction for pacemaker or defibrillator infection: a prospective single center study. Eur J Nucl Med \& Molec Imaging 2018. https://doi.org/10.1007/s00259-018-4142-9

[7] Salomaki SP, Saraste A, Kemppainen J, Bax JJ, Knuuti J, Nuutila $\mathrm{P}$, et al. 18F-FDG positron emission tomography/computed tomography in infective endocarditis. J Nucl Cardiol 2017. https://doi.org/10.1007/s12350-015-0325-y

[8] Balmforth D, Chacko J, Uppal R. Does positron emission tomography/computed tomography aid the diagnosis of prosthetic valve infective endocarditis? Interactive Cardiovasc ThoracSurg 2016; 23: 648-652. https://doi.org/10.1093/icvts/ivw177

[9] Granados U, Fuster D, Pericas JM, Llopis JL, Ninot S, Quintana E et al. Hospital Clinic Endocarditis Study Group. 
Diagnostic Accuracy of 18F-FDG PET/CT in Infective Endocarditis and Implantable Cardiac Electronic Device Infection: A Cross-Sectional Study. J Nucl Med 2016; 57: 1726-1732.

https://doi.org/10.2967/jnumed.116.173690

[10] Gomes A, Glaudemans AWMJ, Touw DJ, van Melle JP, Willems TP, Maass AH, et al. Diagnostic value of imaging in infective endocarditis: a systematic review. Lancet 2017; 17(1): e1-e14.

https://doi.org/10.1016/S1473-3099(16)30141-4

[11] Tanis W, Budde RJP, van der Bilt IAC, Delemarre B, Hoohenkerk G, van Rooden, JK, et al. Novel imaging strategies for the detection of prosthetic heart valve obstruction and endocarditis. Neth Heart J 2016; 24: 96-107. https://doi.org/10.1007/s12471-015-0796-0

[12] Mahmood M, Kendi AT, Ajmal S, Farid S, O'Horo JC, Chareonthaitawee $\mathrm{P}$, et al. Meta-analysis of 18F-FDG $\mathrm{PET} / \mathrm{CT}$ in the diagnosis of infective endocarditis. $\mathrm{J} \mathrm{Nucl}$ Cardiol 2017. https://doi.org/10.1007/s12350-017-1092-8

[13] Roque A, Pizzi MN, Cuéllar-Calàbria H, Aguadé-Bruix $S$. 18F-FDG-PET/CT Angiography for the Diagnosis of Infective Endocarditis. CurrCardiol Rep 2017; 19: 15. https://doi.org/10.1007/s11886-017-0824-3

[14] Kouijzer, IJE, Berrevoets MAH, Aarntzen EHJG, de Vries J, van Dijk APJ, Oyen WJG, et al. 18F-fluorodeoxyglucose positron-emission tomography combined with computed tomography as a diagnostic tool in native valve endocarditis. Nuclear Medicine Communications 2018; 39: 747-752. https://doi.org/10.1097/MNM.0000000000000864

[15] Gomes A, Slart RHJA, Sinha B, Glaudemans AWMJ. 18FFDG PET/CT in the Diagnostic Workup of Infective Endocarditis and Related Intracardiac Prosthetic Material: A Clear Message. J Nucl Med 2016; 57: 1669-1671. https://doi.org/10.2967/jnumed.116.176826

[16] Nuvoli S, Fiore V, Babudieri S, Galassi S, Bagella P, Solinas P, Spanu A, Madeddu G. The additional role of $18 \mathrm{~F}-\mathrm{FDG}$ $\mathrm{PET} / \mathrm{CT}$ in prosthetic valve endocarditis. Eur Rev Med Pharm Sci 2018; 22: 1744-1751.

[17] Murphy DJ, Din M, Hage FD, Reyes E. Guidelines in review: Comparison of ESC and AHA guidance for the diagnosis and management of infective endocarditis in adults. J Nucl Cardiol 2018

https://doi.org/10.1007/s12350-018-1333-5

[18] Jiménez-Ballvé A, Pérez-Castejón MJ, Delgado-Bolton RC, Sánchez-Enrique C, Vilacosta I, Vivas D, et al. Assessment of the diagnostic accuracy of 18F-FDG PET/CT in prosthetic infective endocarditis and cardiac implantable electronic device infection: comparison of different interpretation criteria Eur J Nucl Med Mol Imaging 2016; 43: 2401-2412. https://doi.org/10.1007/s00259-016-3463-9

[19] Fagman E, van Essen M, Lindqvist JF, Snygg-Martin U, Bech-Hanssen O, Svensson G. 18F-FDG PET/CT in the diagnosis of prosthetic valve endocarditis. Int $\mathrm{J}$ Cardiovasc Imaging 2016; 32: 679-686.

https://doi.org/10.1007/s10554-015-0814-8

[20] Juneau D, Golfam M, Hazra S, Erthal F, Zuckier LS, Bernick $\mathrm{J}$, et al. Molecular Imaging for the diagnosis of infective endocarditis: A systematic literature review and metaanalysis. International Journal of Cardiology 2018; 253: 183188.

https://doi.org/10.1016/j.ijcard.2017.10.116

[21] Swart LE, Gomes A, Scholtens AM, Sinha B, Tanis W, Lam MGEH. Improving the Diagnostic Performance of 18FFDGPET/CT in Prosthetic Heart Valve Endocarditis. Circ 2018.

https://doi.org/10.1161/CIRCULATIONAHA.118.035032

[22] Scholtens AM, Swart LE, te Kolste HJ, Budde RPJ, Lam MGEH, Verberne HJ. Standardized uptake values in FDG $\mathrm{PET} / \mathrm{CT}$ for prosthetic heart valve endocarditis: a call for standardization. J Nucl Cardiol 2017 https://doi.org/10.1007/s12350-017-0932-x

[23] Chen W, Dilsizian V. EDITORIAL. FDG PET/CT for the diagnosis and management of infective endocarditis: Expert consensus v. evidence-based practice. J Nucl Cardiol 2018. https://doi.org/10.1007/s12350-018-1398-1

[24] Schindler T. EDITORIAL Another potential step to improve prosthetic heart valve endocarditis imaging with $18 \mathrm{~F}-\mathrm{FDG}$ PET/CT; J Nucl Cardiol 2017. https://doi.org/10.1007/s12350-017-0935-7

[25] Sarrazin JF, Trottier M, Tessier M. Accuracy of PET/CT for detection of infective endocarditis: Where are we now? J Nucl Cardiol 2017. https://doi.org/10.1007/s12350-017-1126-2

[26] Scholtens AM, Budde RPJ, Lam MGEH, Verberne HJ. FDG $\mathrm{PET} / \mathrm{CT}$ in prosthetic heart valve endocarditis: There is no need to wait. J Nucl Cardiol 2017.

https://doi.org/10.1007/s12350-017-0938-4

[27] Scholtens AM, Swart LE, Verberne HJ, Budde RPJ, Lam MGEH. Dual-time-point FDG PET/CT imaging in prosthetic heart valve endocarditis. J Nucl Cardiol 2017. https://doi.org/10.1007/s12350-017-0902-3

[28] Saraste A, Knuuti J. Guidelines in review: Comparison of ESC and AHA guidance for the diagnosis and management of infective endocarditis in adults. Are the differences clinically relevant? The European perspective. J Nucl Cradiol 2018. https://doi.org/10.1007/s12350-018-1414-5

[29] Pizzi MN, Roque A, Cuéllar-Calabria H, Fernández-Hidalgo N, Ferreira-González I, González-Alujas MT, et al. 18F-FDGPET/CTA of Prosthetic Cardiac Valves and Valve-Tube Grafts: Infective Versus Inflammatory Patterns. JACC: Cardiovasc Imaging 2016; 9: 1224-1227. https://doi.org/10.1016/j.jcmg.2016.05.013

[30] Sohail MR, Baddour LM. Role of PET Imaging in Management of Implantable Electronic Device Infection. JACC Cardiovasc Imaging 2016; 9: 291-293. https://doi.org/10.1016/j.jcmg.2015.10.018

[31] Machelart I, Greib C, Wirth G, Camou F, Issa N, Viallard JF, et al. Graft infection after a Bentall procedure: A case series and systematic review of the literature. Diagnostic Microbiology and Infectious Disease 2017; 88: 158-162. https://doi.org/10.1016/j.diagmicrobio.2017.03.002

[32] Erba PA, Lancellotti P, Vilacosta I, Gaemperli O, Rouzet F, Hacker $M$, et al. Recommendations on nuclear and multimodality imaging in IE and CIED infections. Eur $\mathrm{J} \mathrm{Nucl}$ Med \& Molec Imaging 2018 https://doi.org/10.1007/s00259-018-4025-0

[33] Aguadé Bruix S, Roque Pérez A, Cuéllar Calabria H, Pizz MN. Cardiac 18F-FDG PET/CT procedure for the diagnosis of prosthetic endocarditis and intracardiac devices. Rev Esp Med Nucl Imagen Mol 2018; 37: 163-171. https://doi.org/10.1016/j.remn.2018.01.002

[34] Mikail N, Benali K, Mahida, B, Vigne J, Hyafil1 F, Rouzet F, et al. 18F-FDG-PET/CT Imaging to Diagnose Septic Emboli and Mycotic Aneurysms in Patients with Endocarditis and Cardiac Device Infections. Current Cardiology Reports 2018; 20: 14 .

https://doi.org/10.1007/s11886-018-0956-0

[35] Amroui S, Tlili G, Sohal M, Berte B, Hindié E, Ritter P, et al. Contribution of PET Imaging to the Diagnosis of Septic Embolism in Patients With Pacing Lead Endocarditis. J Am Coll Cardiollmag 2016; 9: 283-290. https://doi.org/10.1016/j.jcmg.2015.09.014

[36] Kokalova A, Dell'aquila AM, Avramovic N, Martens $S$, Wenning C, Sindermann JR. Supporting imaging modalities for improving diagnosis of prosthesis endocarditis: preliminary results of a single-center experience with 18FFDG-PET/CT. Minerva Med. 2017; 108: 299-304. doi: 10.23736/S0026-4806.17.04976-X. 
[37] Ariaans MBPA, Roovers EA, Claassen MAA, Hassing RJ, Swanink CMA, Gisolf EH. Increased overall survival after introduction of structured bedside consultation in Staphylococcus aureus bacteraemia. Eur J Clin Microbiol \& Inf Dis 2018; 37: 1187-1193. https://doi.org/10.1007/s10096-018-3239-1

[38] Kouijzer IJE, Kampschreur LM, Wever PC, Hoekstra C, van Kasteren MEE, de Jager-Leclercq MGL, et al. The Value of 18F-FDG PET/CT in Diagnosis and During Follow-up in 273 Patients with Chronic Q Fever. J Nucl Med 2018; 59: 127133.

https://doi.org/10.2967/inumed.117.192492
[39] Pizzi MN, Dos-Subirà L, Roque A, Fernández-Hidalgo N, Cuéllar-Calabria $\mathrm{H}$, Domènech AP, et al. 18F-FDG-PET/CT angiography in the diagnosis of infective endocarditis and cardiac device infection in adult patients with congenital heart disease and prosthetic material. International Journal of Cardiology 2017; 48: 396-402.

https://doi.org/10.1016/j.ijcard.2017.08.008

[40] Gomes A, van Geel PP, Santing M, Prakken NJ, Ruis ML, van Assen $\mathrm{S}$, et al. Imaging infective endocarditis: Adherence to a diagnostic flowchart and direct comparison of imaging techniques. J Nucl Cardiol 2018.

https://doi.org/10.1007/s12350-018-1383-8

Received on 14-10-2018

Accepted on 23-10-2018

Published on 04-11-2018

http://dx.doi.org/10.15379/2410-2822.2018.05.02.01

(c) 2018 Wilhelm P. Mistiaen; Licensee Cosmos Scholars Publishing House.

This is an open access article licensed under the terms of the Creative Commons Attribution Non-Commercial License

(http://creativecommons.org/licenses/by-nc/3.0/), which permits unrestricted, non-commercial use, distribution and reproduction in any medium, provided the work is properly cited. 